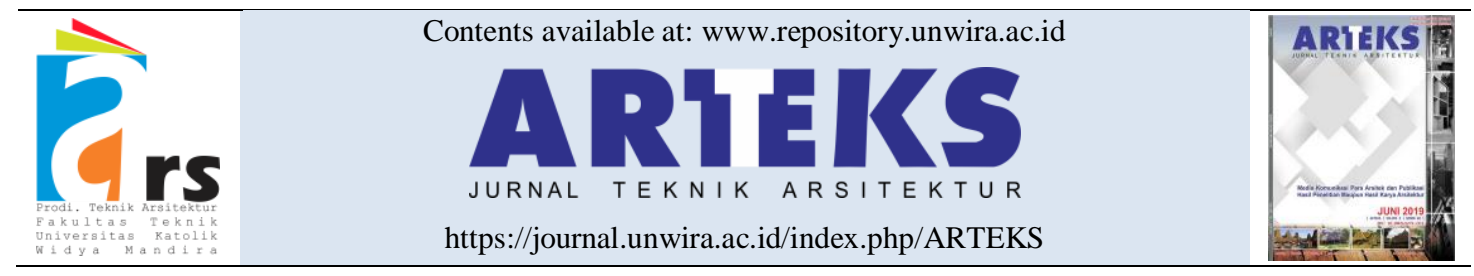

Research paper

doi: http://doi.org/10.30822/arteks.v5i2.403

\title{
Pengaruh perubahan sirkulasi terhadap fungsi ruang di rumah Peranakan, Kampung Babagan, Lasem
}

\author{
Tessa Eka Darmayanti ${ }^{1,2 *}$, Azizi Bahauddin ${ }^{2}(\mathbb{D}$ \\ ${ }^{1}$ Program Studi Desain Interior, Fakultas Seni Rupa dan Desain, \\ Universitas Kristen Maranatha, Jl. Pro. Surya Sumantri, no. 65, Bandung 40164, Indonesia \\ ${ }^{2}$ School of Housing, Building, and Planning, \\ Universiti Sains Malaysia, 11800, Penang, Malaysia
}

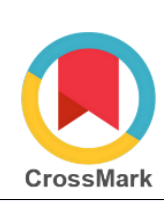

\begin{tabular}{l}
\hline ARTICLE INFO \\
\hline Article history: \\
Received February 29, 2020 \\
Received in revised form March 03, \\
2020 \\
Accepted April 28, 2020 \\
Available online August 01, 2020
\end{tabular}

Keywords:

Kidang Mas house circulation

Kidang Mas spatial function

Lasem

Peranakan house

Sustainable culture

*Corresponding author: Tessa Eka

Darmayanti

Program Studi Desain Interior, Fakultas Seni

Rupa dan Desain, Universitas Kristen

Maranatha, Indonesia

Email: tessaeka82@gmail.com

ORCID: https://orcid.org/0000-0001-8705-

1131

\section{ABSTRACT}

Effects of changes in circulation on spatial function in peranakan house, Babagan Village, Lasem

A change could affect circulation in a building. The change may be influenced by external or internal sources that are related to the perspective of tradition, culture and social surroundings. It may indirectly presents a new feature that can accommodate the needs of residents and this happens in one of the Peranakan houses in Lasem. It could be seen as a form of conservation while respecting family and social traditions and culture. The purpose of this study is to understand which components that influence changes in the circulation of space within the Peranakan-Kidang Mas housing complex which includes the main building, courtyard, kitchen, and workshop. To answer these objectives, the methods used are surveys, interviews, and observation. This narrative research discussion is supported by a spatial concept and research findings show that changes in circulation make it possible to give new meaning to the function of a space.

\section{Pendahuluan}

Ruang sebagai salah satu komponen arsitektur yang memiliki peranan penting dalam membina hubungan perilaku yang berada di dalamnya dengan lingkungan sekitarnya, karena fungsinya sebagai wadah kegiatan manusia (Hartono 2019). Pelbagai kegiatan manusia mampu ditampung pada wadah yang berukuran besar seperti kota atau kampung, sampai yang berukuran lebih personal seperti rumah. Pernyataan tersebut sesuai dengan bahasan artikel ini yang akan menguraikan wadah bernama Lasem, Babagan, Rumah Peranakan dan Kidang Mas.
"Lasem adalah sebuah kota ketjil jang terletak di sebelah Timur Laut Djateng. Kota ini adalah sebuah kota lama, ternjata dengan telah disebut-sebutnya kota ini dalam babad lama. Penduduk kota ini sebagian besar adalah orang-orang Tionghoa jang sekaligus djuga menguasai perekonomiannja. Dengan rumahrumah mereka jang dikelilingi oleh temboktembok jang tinggi dan kukuh..." (Nur 1955).

Merujuk pada berita majalah Teruna yang ditulis oleh Abdul Nur, 1955, Lasem telah dikenal dari 65 tahun lalu, terutama dengan keberadaan rumah-rumah Peranakan Tionghoa di kawasan Pecinan. Bahkan, sumber lebih lawas yaitu kitab Nagarakertagama mencatat bahwa Lasem dikenal 
pada masa pemerintahan Hayam Wuruk dari Kerajaan Majapahit dan naskah Babad Lasem menyatakan sejak masa itu, Lasem telah menjadi kota pelabuhan yang ramai (Djafar 1978; Nastiti and Rangkuti 1988). Kejayaannya terus berlangsung ketika Belanda menguasai Indonesia pada abad ke-19, Lasem tetap memiliki karisma sebagai kota pelabuhan dan pernah menjadi pusat perdagangan opium yang ketika itu legal diperdagangkan. Selain itu, Lasem dikenal sebagai tempat imigran dari Tiongkok terbesar di Jawa bahkan sebelum Laksamana Cheng Ho datang (Suroyo 1994; Handinoto 2015; Utomo 2017).

Berdasarkan latar belakang sejarah yang luar biasa, Lasem menjadi bagian dari warisan sejarah dan budaya, salah satunya adalah perwujudan rumah-rumah Peranakan yang umumnya tersebar di tiga kampung Pecinan yaitu Soditan yang terbentuk sekitar tahun 1479-an, sedangkan Karangturi pada tahun 1740-an dan Babagan sekitar tahun 1800-an (Darmayanti 2017).

Penelitian ini, akan dibahas satu rumah Peranakan yang terletak di Kampung Babagan yaitu Kidang Mas. Kampung Babagan dikenal dengan sebutan kampung batik karena sebagian besar pekerjaan utama masyarakat adalah pengrajin batik tulis. Kidang Mas dipilih bukan karena paling indah arsitekturnya, paling tua usia bangunannya atau paling dikenal di Lasem. Tetapi, rumah ini terlihat dirawat dan 'hidup,' karena sebagian besar generasinya tinggal di rumah tersebut dan melanjutkan bisnis batik tulis. Bisnis tersebut, menyebabkan rumah Peranakan Kidang Mas memiliki kegiatan privat seperti kegiatan keluarga dan kegiatan publik yang melibatkan orang-orang dari luar seperti pengrajin batik atau orang-orang yang tertarik dengan batik, baik pembeli atau peneliti. Faktor lain yang mendukung pemilihan rumah ini adalah keramahan dan antusiasme pemilik rumah untuk berbagi cerita dan informasi tentang apa saja yang terjadi di rumah dan tentang budaya di sekitarnya. Ini penting, karena sulit untuk menemukan kepribadian seperti itu di Lasem (Darmayanti and Bahauddin 2019).

Dilihat dari cara pembangunannya, terdapat dua metode konstruksi yang diterapkan pada rumah Peranakan di Lasem. Pertama, membangun dinding di sekeliling komplek, membangun bangunan di dalamnya dan gerbang. Kemudian, cara kedua yaitu membangun dinding di sekeliling komplek, membuat gerbangnya, baru membangun bangunan di dalamnya. Bangunan utama dibangun di tengah-tengah komplek, kemudian dikelilingi oleh bangunan-bangunan lainnya dan di antara bangunan-bangunan akan terbentuk halaman depan dan belakang (Nas 2002). Tata letak ruang, rumah Peranakan (bangunan utama) di Lasem memiliki persamaan dengan rumah tradisional Jawa, yaitu bentuk denah yang simetris; memiliki teras depan yang luas; empat kamar tidur dengan posisi yang sama (sisi kiri dan kanan); terdapat ruang penting yang ditempatkan pada bagian tengah paling depan rumah yakni ruang altar pada rumah Peranakan dan omah jero pada rumah Jawa; ruang berkumpul keluarga di bagian belakang dan adanya teras belakang (Purwanto and Titiek S. 2017). Pernyataan tersebut terselip informasi bahwa, walaupun terdapat beberapa sirkulasi dan fungsi ruang yang berbeda, namun terlihat adanya akulturasi budaya pada rumah Peranakan di Lasem, yaitu Tionghoa dan Jawa. Perpaduan budaya Tionghoa tidak saja melibatkan budaya lokal Jawa, namun juga budaya Eropa - Belanda, oleh karena itu, Rachmayanti et al (2017) dan Sudarwani et al (2018) membagi rumah Peranakan di Lasem menjadi dua kategori yaitu rumah dengan pengaruh asli Tionghoa dan pengaruh gaya Kolonial Belanda (Rachmayanti, Rusli, and Wulandari 2017; Sudarwani, Purwanto, and Rukhayah 2018).

Isu penelitian ini adalah fenomena "alih fungsi" yaitu perubahan fungsi rumah-rumah Peranakan di Lasem. Namun, terdapat "kesalahpahaman" dalam membuat perubahan tersebut dengan kurang atau tidak mempertimbangkan cultural-historical value yang ada di dalamnya, sehingga secara fisik terlihat "baik" tetapi tidak menarik, karena telah kehilangan jiwanya. Perubahan tersebut yakni: (a) hunian menjadi fasilitas yang bersifat (b) nonhunian dan juga komersil, atau gabungan keduanya $(\mathrm{a}+\mathrm{b})$. Contoh fasilitas komersil dan nonhunian adalah toko batik, penginapan, rumah makan, museum, pabrik, gudang atau workshop batik. Artinya, jika terjadi penggabungan fungsi maka, dapat dipastikan adanya perubahan kegiatan, yang memengaruhi sirkulasi di dalamnya, kemudian memberikan dampak pada fungsi ruang. Melalui penelitian ini, diharapkan dapat memberi gambaran tentang perubahanperubahan yang terjadi berdasarkan aktivitas, namun tetap menjaga nilai-nilai sejarah, tradisi dan budaya di dalamnya. Dengan menjaga eksistensi nilai arsitektural maka identitas rumah dan penghuni dapat dipertahankan (Sukada and 
Salura 2020; Arinto 2018; Sumardiyanto 2019). Sehingga, terciptanya keberlanjutan 'hidup' rumah Peranakan Lasem.

Pertanyaan penelitian untuk 'membuka' cara pandang tekstual (dengan adanya interpretasi) dan kontekstual (dengan menyertakan informasi sejarah maupun latar belakang yang bersifat general) untuk mengkaji suatu fungsi dan makna pada ruang berdasarkan pelbagai sirkulasi di dalam rumah Peranakan, maka dirumuskan sebagai berikut:

a. Bagaimana dan apa saja yang memengaruhi perubahan sirkulasi ruang-ruang di dalam rumah Peranakan Kidang Mas?

b. Bagaimana sirkulasi memengaruhi fungsi ruang?

\section{Metode penelitian}

Penelitian kualitatif ini diawali setelah melakukan pilot study pada akhir tahun 2017 dan didukung pencarian data dengan studi literatur, kemudian melakukan observasi lapangan dan wawancara secara mendalam dengan penghuni rumah pada Desember 2018, Juli 2019 dan Desember 2019. Proses-proses pengambilan data tersebut sesuai dengan kaedah penelitian kualitatif, yaitu berdasarkan pada data primer yang diperoleh langsung dari sumbernya. Peneliti merupakan instrumen utama karena tugasnya memperhatikan proses dan produknya (Bogdan and Biklen 1992).

Data yang terkumpul dianalisis dengan pendekatan konsep spasial dan dijelaskan secara naratif. Melalui naratif, ruang tidak lagi dilihat sebagai wadah yang statis tetapi sebagai ruang yang dialami oleh manusia (D. J. Smith 2001; Sudradjat 2020). Naratif adalah strategi penelitian yang melibatkan proses bercerita segala pengalaman yang berkaitan dengan budaya dan dapat membentuk pemahaman baru terhadap objek penelitian (Bahauddin 2017).

Ketika wawancara di rumah, dapat dilihat adanya perubahan sirkulasi ruang pada rumah Peranakan Kidang Mas di Kampung Babagan, Lasem. Perubahan tersebut dikarenakan, rumah Peranakan Kidang Mas bukan sekadar sebagai hunian tetapi sebagai workshop kerajinan batik tulis khas Lasem, sehingga kegiatan yang ada tidak saja bersifat pribadi yang melibatkan keluarga, tetapi juga publik yang telah melibatkan pengguna ruang nonkeluarga (Darmayanti and Bahauddin 2019). Rumah Peranakan Kidang Mas dipilih sebagai objek penelitian bukan karena yang paling tua usianya, sejarahnya yang paling terkenal dikalangan masyarakat lokal atau batiknya yang paling indah di Lasem. Tetapi karena telah dihuni sejak generasi pertama dan saat ini didiami oleh tiga generasi yaitu generasi kelima yaitu Tan Gwan Ling, dipanggil pak Gunawan dan Tjan Djoen Nio atau dipanggil ibu Kian, kemudian generasi keenam adalah anak bungsu dari mereka yaitu Bapak Rudi Siswanto beserta istri dan dua anaknya sebagai generasi ketujuh. Selain itu, usaha kerajinan batik diteruskan secara turun temurun dan bertahan hingga saat ini. Konsistensi tersebut menjadi daya tarik Kidang Mas yang sulit ditemukan di rumah Peranakan lainnya di Lasem.

Fokus analisis atau unit amatan meliputi bangunan utama, courtyard, dapur dan workshop batik. Keempat area tersebut memiliki peranan penting dalam mengakomodasi kegiatan seharihari sebagai keluarga dan sebagai pengrajin batik. Analisis awal yang dilakukan adalah identifikasi sirkulasi, pelbagai kegiatan yang dilakukan di dalamnya, apa fungsi ruang tersebut dan memberikan makna apa terhadap penghuni atau orang yang berada di dalamnya. Kemudian, dievaluasi fungsi ruang terhadap perubahan sirkulasi yang terjadi serta memetakan faktor apa saja yang mempengaruhi fungsi ruang. Hasil analisis yang diperoleh, kemudian diinterpretasikan faktor dan dampak perubahan sirkulasi terhadap fungsi serta makna ruang.

\section{Temuan dan pembahasan}

\section{Interpretasi perubahan sirkulasi dan fungsi ruang}

Pada awalnya proses membatik terjadi di luar rumah, kain batik yang sudah digambar dijemput ke rumah oleh pengrajin batik atau obeng untuk dicanting, hasil canting batik oleh obeng diantar kembali ke rumah Peranakan Kidang Mas untuk dilanjutkan proses pewarnaan. Proses pewarnaan di rumah Peranakan Kidang Mas bertujuan agar resep warna dan pewarnaan tetap terjaga di dalam rumah. Untuk mempercepat proses pewarnaan, maka terjadi perubahan dengan "mengundang" obeng ke rumah dan mengerjakan seluruh prosesnya di dalam kompleks rumah. Awalnya hanya satu atau dua, sekarang sudah ada puluhan obeng. 
Setelah proses membatik selesai, dilanjutkan dengan penjualan dengan melalui proses melipat dan mengepak kain-kain batik yang akan dijemput oleh para tengkulak batik dari Lasem bahkan dari luar Lasem. Selain itu, ada juga pengiriman kain-kain batik yang umumnya ke daerah Jawa Timur namun ada juga pesanan dari luar negeri seperti Malaysia dan Singapura. Seiring waktu berjalan, pecinta atau kolektor kain batik tidak lagi menunggu dikirim kain batik, tapi pecinta atau kolektor batik menjemput kainnya ke rumah. Sehingga, lebih leluasa melihat langsung, berkonsultasi, menyentuh kain, memilih bahkan mencobanya.

Pelbagai kegiatan di rumah Peranakan Kidang Mas melibatkan banyaknya pergerakan manusia, yang berlangsung terus menerus, sehingga perlahan terjadi perubahan-perubahan mengikuti perkembangan usaha kerajinan batik tulis Kidang Mas. Pergerakan aktivitas tersebut meninggalkan jejak-jejak yang disebut sebagai sirkulasi. Jejakjejak dapat menjadi bagian dari kisah hidup penghuni dan orang yang mengalami di dalamnya yang merupakan warisan bagi generasi mendatang (Darmayanti and Bahauddin 2019). Soja (1998) memberikan pencerahan terhadap pernyataan di atas bahwa pergerakan orang, barang dan informasi menciptakan ruang persepsi dan mampu memberikan kesan tersendiri (Soja 1998).

Berdasarkan penelitian Darmayanti (2019), diketahui bahwa perubahan sirkulasi asli dipengaruhi oleh tiga faktor, yaitu ekonomi, sosial dan budaya di dalam keluarga (Darmayanti and Bahauddin 2019). Masing-masing faktor mempunyai alasan dan respon, yaitu: (1) Faktor ekonomi yang memengaruhi perubahan ketika Indonesia mengalami krisis ekonomi pada tahun 1997, sehingga berdampak pada sektor bisnis, begitu juga yang terjadi di Kidang Mas. Memantapkan kerajinan batik tulis menjadi usaha utama keluarga adalah respon untuk menghadapi krisis ekonomi. Usaha kerajinan batik tulis menyebabkan pekerja masuk ke dalam komplek rumah; (2) Faktor sosial, terjadi karena rumah Peranakan Kidang Mas termasuk bangunan yang menyimpan nilai-nilai budaya dan sejarah. Selain itu, sebagai tempat pembuatan dan penjualan batik tulis Lasem menjadi daya tarik perhatian para peneliti, penggemar sejarah dan turis untuk mengunjunginya; (3) Faktor budaya keluarga terbentuk pada tahun 2014, ketika Rudi meminta istrinya pindah ke Lasem untuk menetap dan meneruskan usaha batik tulis sebagai warisan budaya keluarga. Sebelum pindah ke Lasem dari Jakarta, dibangun sebuah kamar mandi di dalam area bangunan utama (teras belakang) yang merupakan permintaan dari istri.

Berdasarkan observasi di lapangan, tidak ada perubahan bentuk atau dimensi ruangan. Hanya saja jalur sirkulasinya lebih padat dikarenakan untuk mengakomodasi kegiatan-kegiatan baru yang memerlukan jalur-jalur sirkulasi baru di dalam rumah Peranakan Kidang Mas.

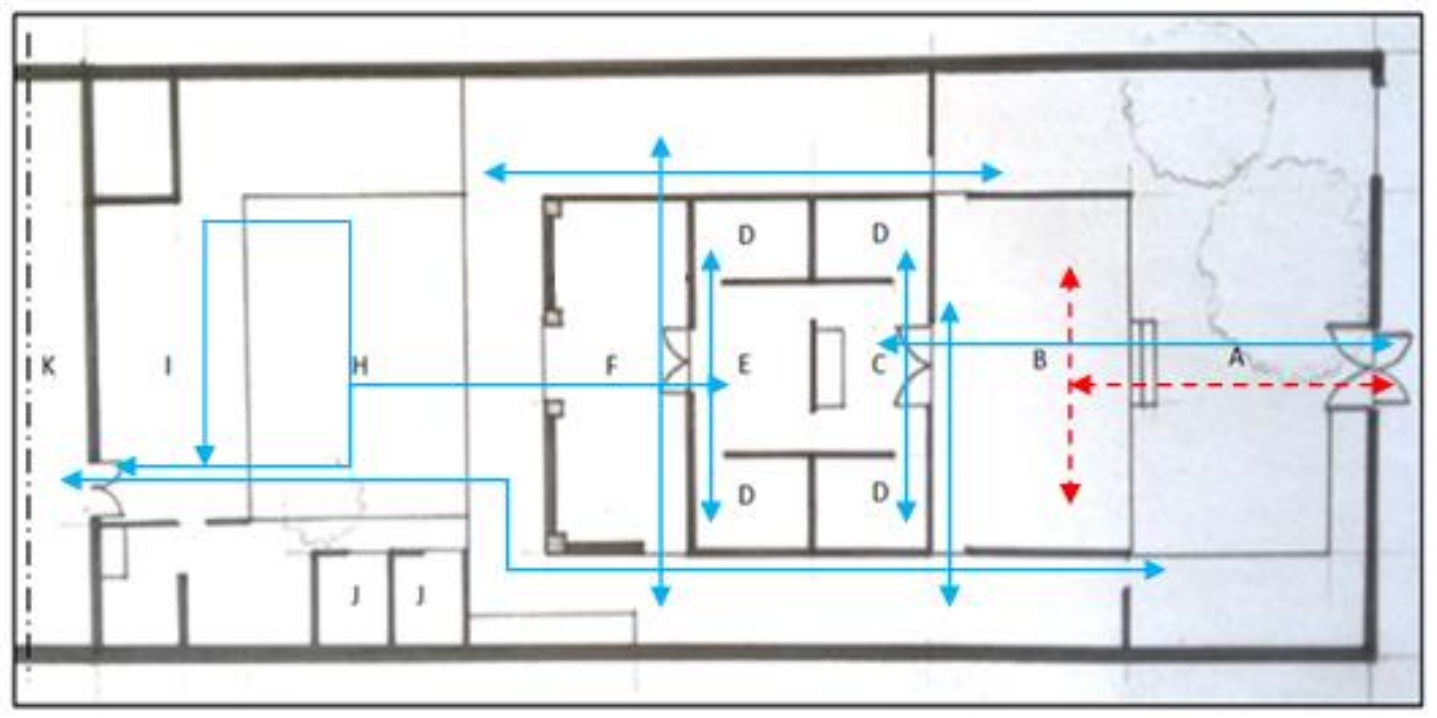

Denah awal (a) - Kidang mas 


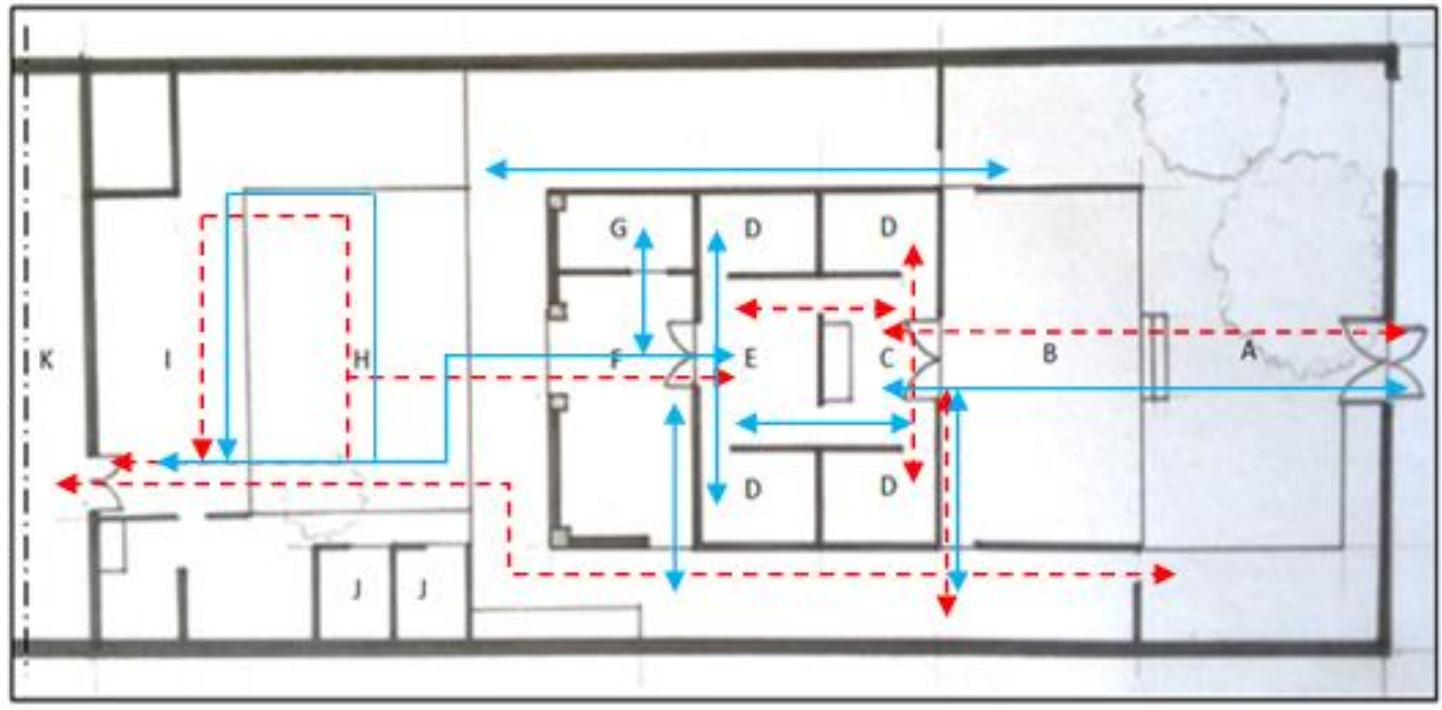

Keterangan:

Denah perubahan (b) - Kidang mas

A. Taman depan; B. Serambi depan; C. Prayer Hall; D. Kamar tidur; E. Ruang keluarga; F. Serambi belakang; G. Kamar mandi; H. Courtyard; I. Dapur; J. Kamar mandi luar; K. Workshop

Gambar 1. Denah komplek rumah kidang mas: denah awal (a/atas); denah perubahan (b/bawah)

Perubahan sirkulasi juga memengaruhi perilaku. Para tamu juga tidak lagi disambut dengan formal tetapi lebih hangat dan kekeluargaan. Kemudian, tamu tidak lagi duduk rapi di kursi-kursi yang tersedia tetapi dapat menikmati duduk santai di lantai (Lihat gambar 2).
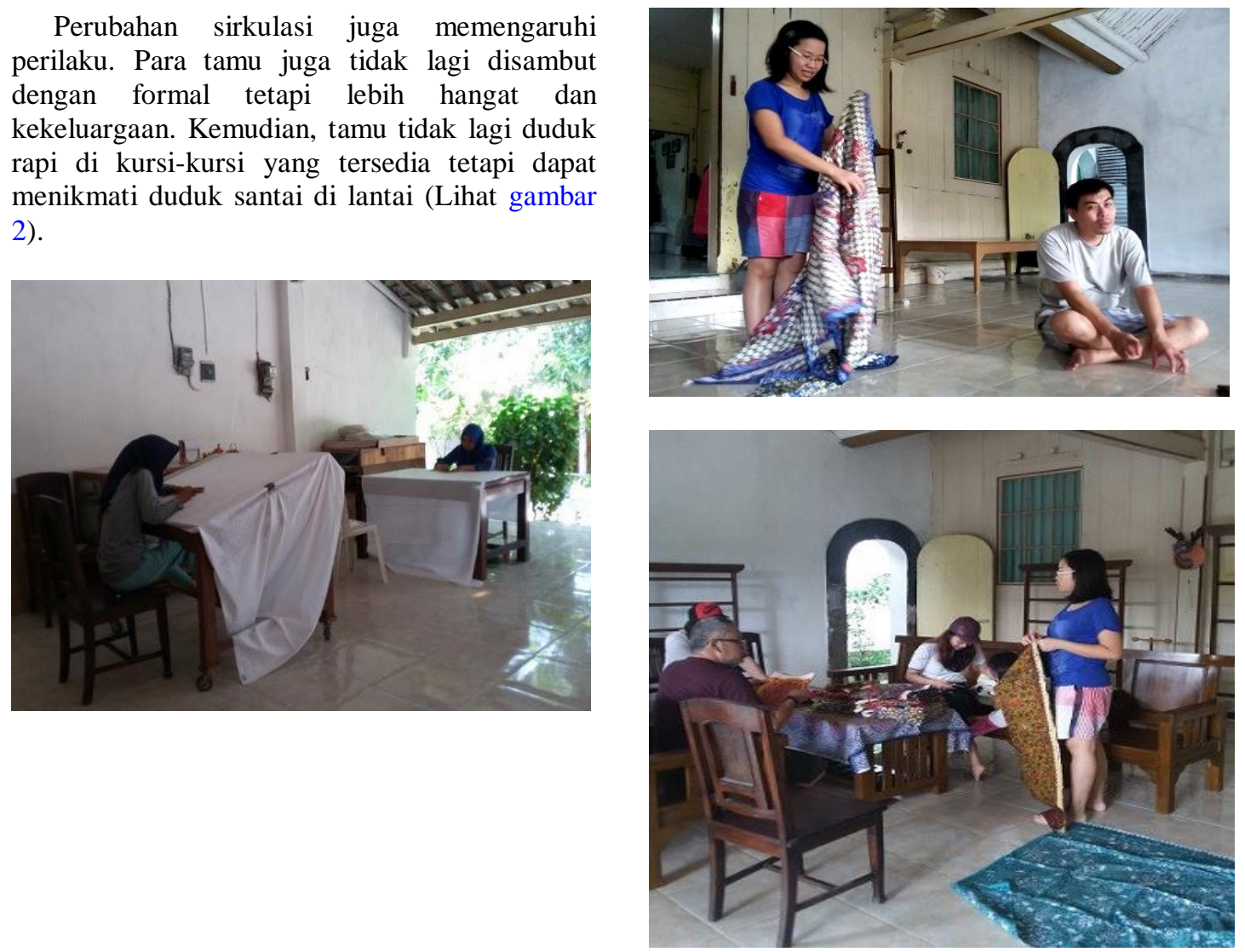

Gambar 2. Kegiatan di serambi depan 
Serambi juga dapat diinterpretasikan sebagai area bermain atau relaksasi untuk anak-anak pak Rudi (pemilik rumah). Biasanya digunakan untuk bermain sepeda atau sekadar menikmati video online, sedangkan untuk anak kedua dijadikan sebagai arena belajar berjalan (masih bayi) (Lihat gambar 3).
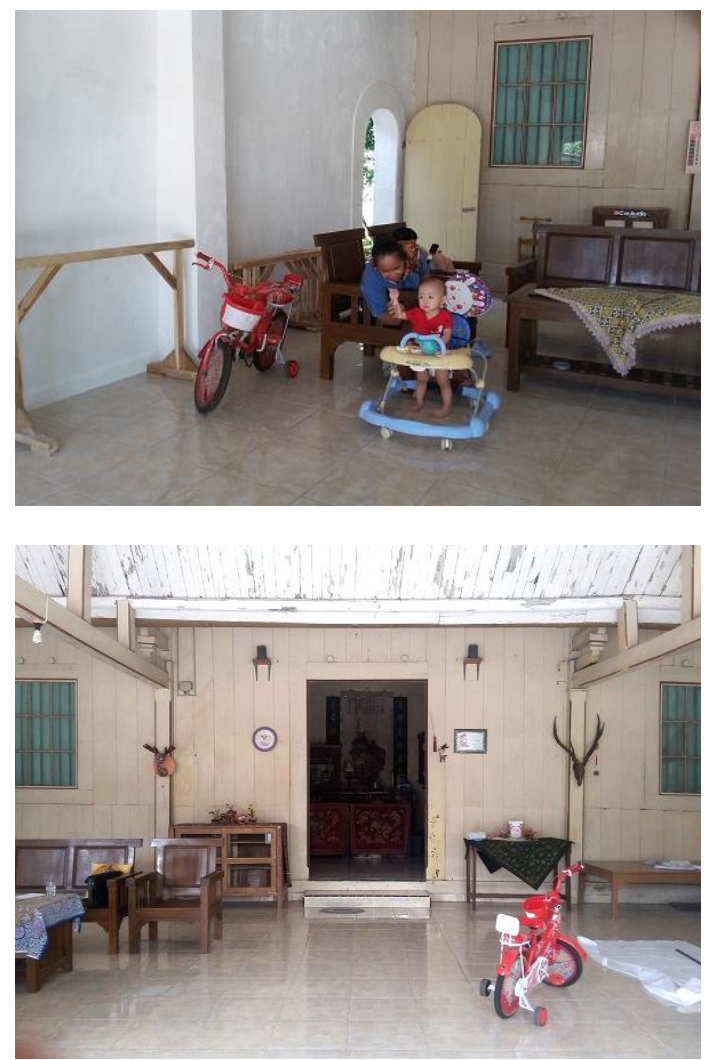

Gambar 3. Serambi depan dijadikan area bermain

Berdasarkan penjelasan di atas, perubahan sirkulasi memberikan makna yang lebih spesifik pada serambi depan. Adanya interaksi sosial yang dinamis antara penghuni rumah, pengrajin dan tamu. (1) Ruang Tamu. Tamu yang diterima di serambi terbagi dalam beberapa kategori, yaitu pembeli atau pecinta batik dan peneliti batik atau peneliti bangunan rumah Peranakan di Lasem. Tamu yang datang tidak terbatas dari dalam negeri saja tetapi ada yang dari luar negeri. Sehingga, fungsi ruang menjadi bertambah yaitu sebagai wadah pertukaran budaya; (2) Prayer hall yang terdiri dari altar sembahyang. Area ini berada di dalam bangunan utama bagian tengah paling depan. Keberadaan altar digunakan untuk mengabdikan kehidupan religius orang-orang tradisional Tionghoa (R. J. Smith 2015). Praktik tersebut diwarisi secara turun-temurun dari era tradisional Konfusianisme sampai ke era neoKonfusianisme. Konsep praktik ini adalah kepercayaan pada kehidupan di dunia setelah kematian (Lukman, Setyoningrum, and Risamntojo 2018).

Di altar terdapat foto generasi pertama, Mak Klepon yang diceritakan sebagai seorang perempuan Jawa dan suaminya yang berasal dari daratan Tiongkok yaitu Engkong Tay Tjian. Pada saat wawancara dengan istri pak Rudi yaitu mba Vina, penulis bertanya kenapa untuk pihak suami yang dipajang adalah hasil sketsa wajah, alasannya adalah tidak ada dokumentasi fotografi, sekaligus yang bersangkutan pergi ke Tiongkok dan tidak kembali lagi (Lihat gambar 4).

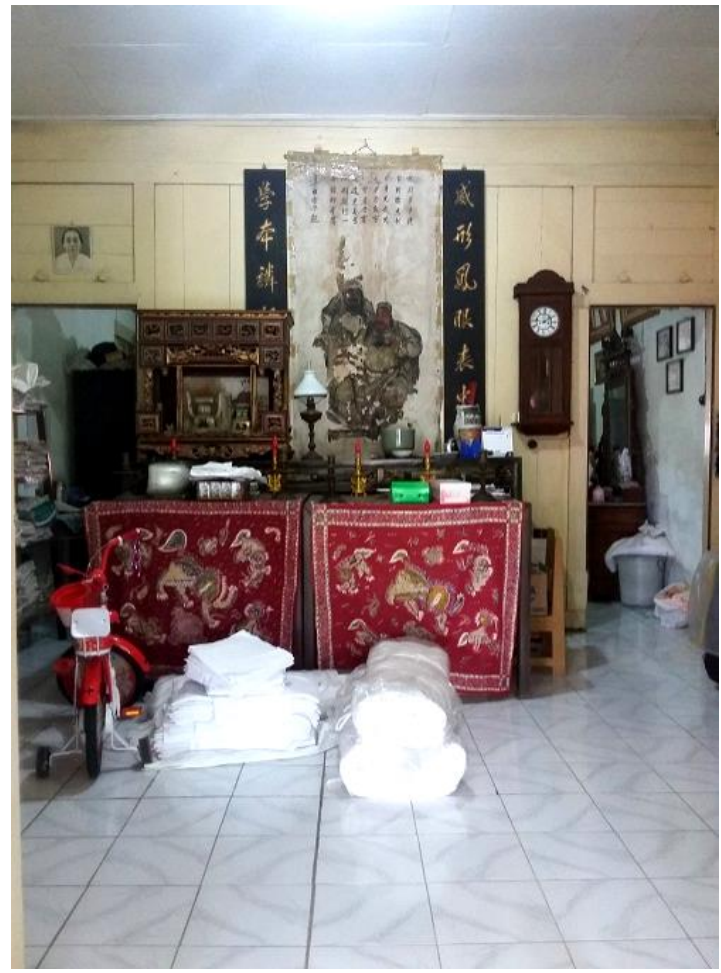

Gambar 4. Prayer hall-kidang mas

Kisah dari percakapan tersebut secara tidak langsung menciptakan putaran sirkulasi informasi tentang sejarah dan budaya yang terjadi di keluarga tersebut. Dengan adanya sirkulasi informasi yang bersifat intangible, maka secara tidak langsung, di area altar telah terbentuk "ruang" tersendiri karena hal itu tentu saja memberikan makna personal yang mendalam pada setiap generasinya sekaligus dapat membangun sense of attachment dengan leluhur dan juga rumah. Seperti yang dikatakan Kant 
(1770) bahwa ruang tidak selalu bersifat objektif atau terlihat dengan mata, tetapi dapat bersifat subyektif sebagai hasil perasaan atau pikiran manusia (Kant 1770).

Pada awalnya, area altar hanya menjadi tempat sembahyang dan berdoa anggota keluarga. Walaupun, sekarang hanya ibu Kian yang melakukan ritual sembahyang di altar karena anggota keluarga yang lain telah memeluk agama Kristen. Melalui wawancara dengan pak Rudi, ibu Kian tetap berpegang teguh pada kepercayaannya karena ingin tetap memelihara dan "berhubungan" tidak saja dengan roh orang tuanya, tetapi juga dengan leluhurnya.

Perubahan terjadi pada area ini ketika pekerja atau pengrajin batik masuk melewati area ini untuk menyimpan atau mengambil persediaan kain-kain mori dan batik yang sudah jadi. Pernah juga terjadi kegiatan pemilihan kain-kain batik kepada pembeli yang dilakukan di depan area altar; (3) Kamar tidur. Terdapat empat kamar tidur yaitu dua di depan, dekat dengan serambi depan dan prayer hall dan dua di belakang, dekat dengan ruang keluarga dan serambi belakang. Dahulu, seluruh kamar digunakan sesuai fungsinya oleh anak-anak generasi keempat, namun keadaan berubah setelah sebagian besar anaknya pindah dari rumah karena menikah, sedangkan anak bungsu (ibu Kian) tetap tinggal sampai sekarang. Ibu Kian dengan suami menempati salah satu kamar tidur di belakang, begitu juga dengan Pak Rudi, istri dan anak-anaknya menempati kamar tidur belakang yang lainnya. Pada saat pengambilan dokumentasi visual untuk kamar tidak diizinkan, tindakan tersebut seperti bukti bahwa secara tidak disadari adanya kebutuhan dasar terbentuknya ruang, terutama yang bersifat privat yaitu kenyamanan dan rasa aman. Dua perasaan tersebut termasuk pada perasaan teritorial, hasil hubungan paling penting antara manusaia dengan ruang (Wilson 1972).

Kemudian, adanya perubahan sirkulasi yang terjadi di dua kamar depan, orang non-keluarga dapat keluar-masuk kamar yang menyebabkan berubahnya fungsi ruang dari kamar tidur menjadi tempat penyimpanan bahan baku keperluan batik dan juga barang-barang keluarga. Hal tersebut yang mendasari perubahan sifat ruang dari privat ke semi-privat; (4) Ruang keluarga berada dibelakang area prayer hall dengan pembatas dinding kayu. Ruang ini masih digunakan sesuai dengan fungsinya yaitu tempat berkumpul keluarga atau area nonton televisi. Namun sirkulasinya telah berubah, yang semula hanya untuk keluarga saja menjadi semi-privat karena pekerja diperbolehkan masuk untuk membersihkan dan membereskan ruangan.

Berdasarkan wawancara dengan Pak Rudi pada Juli 2019. Semasa kecil, setiap sore selalu duduk diruangan tersebut dengan kedua kakak laki-lakinya untuk menonton film kesayangan atau hanya sekadar makan kudapan yang telah disediakan. Untuk Pak Rudi, dengan melihat ruang keluarga membawa memorinya ke masa kecilnya. Pernyataan beliau mengingatkan pada arsitek Finlandia, Juhani Pallasmaa (2009) yang menjelaskan hubungan mendalam antara memori dan arsitektur yaitu bagaimana manusia memahami dan mengingat siapa dirinya, apa saja yang manusia lakukan melalui konstruksi, baik materi maupun mental dan ingatan manusia adalah ingatan situasional dan spasial (Pallasmaa 2009); (5) Serambi belakang merupakan area yang mempunyai akses ke courtyard atau taman (area terbuka) di tengah komplek rumah. Sebelumnya area serambi belakang digunakan sebagai area tempat duduk-duduk untuk mimum atau membaca majalah/koran sambil menikmati suasana harian. Diperkirakan sirkulasi yang terjadi tidak terlalu aktif setiap harinya. Namun, ketika melakukan studi penelitian lapangan, terlihat bahwa sirkulasi di serambi belakang cenderung aktif, banyak fasilitas (tambahan) untuk beberapa kegiatan seperti, makan, mencuci pakaian, melipat dan packing kain-kain batik untuk dikirim atau disimpan serta kegiatan mandi (di kamar mandi yang dibuat pada tahun 2014, ketika istri dan anak Pak Rudi pindah dari Jakarta ke Lasem untuk menetap) (Lihat gambar 5). Hasil analisis mendapatkan kesimpulan bahwa serambi belakang menjadi ruang multifungsi dan menjadi sentral kegiatan keluarga dan usaha batik.

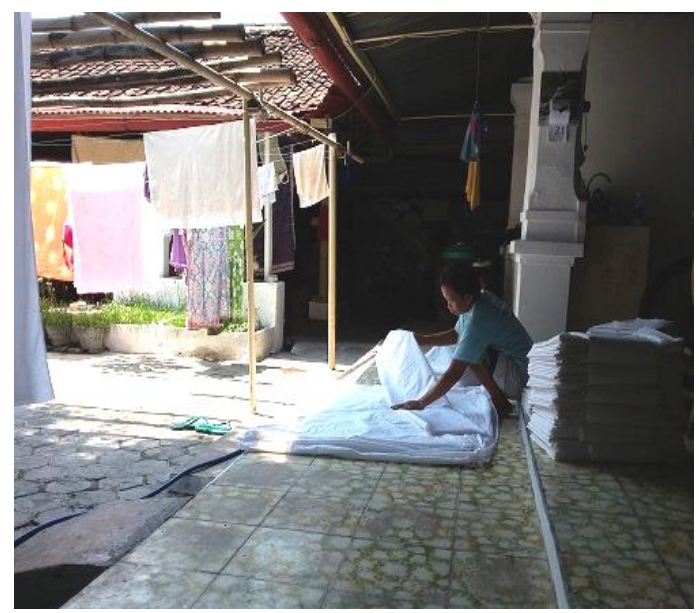



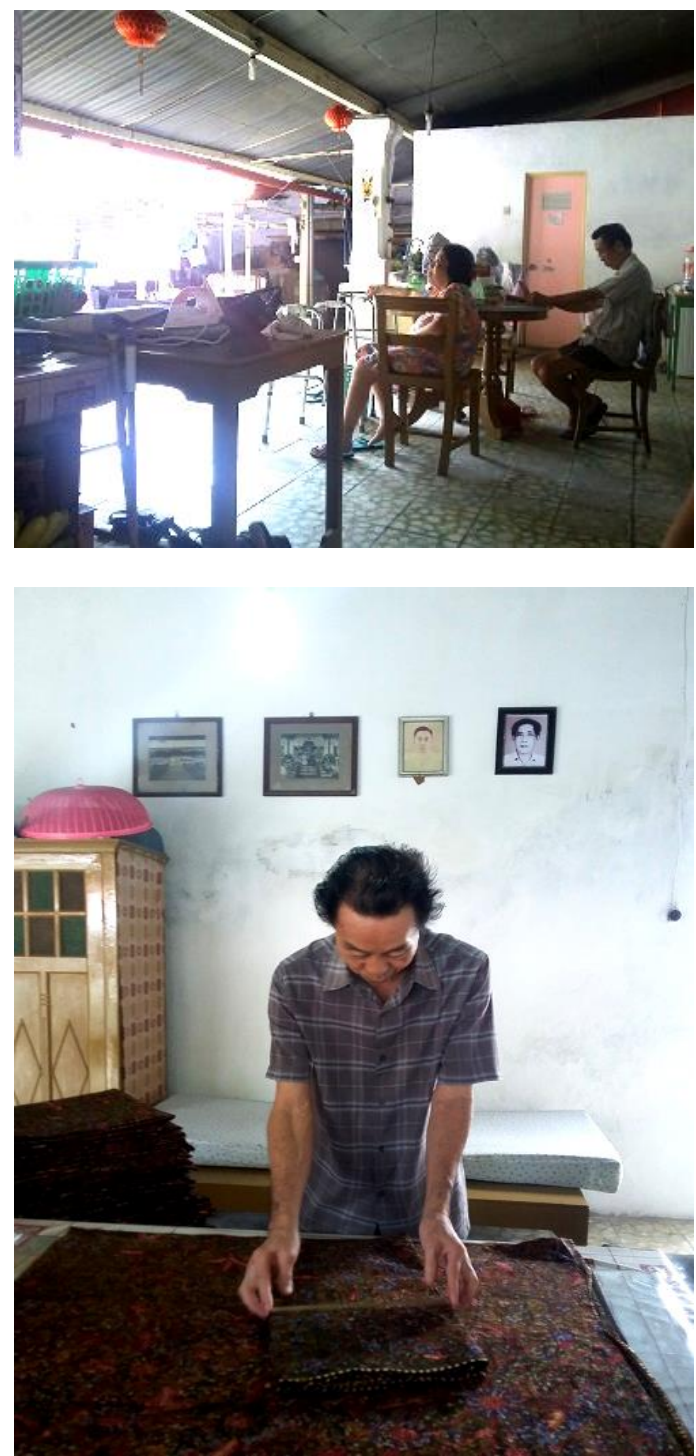

Gambar 5. Kegiatan di serambi belakang

Setelah membahas perubahan sirkulasi yang ada di dalam bangunan utama, kemudian ke area courtyard. Area courtyard cukup luas untuk menampung kegiatan outdoor bersama keluarga. Menurut ibu Vina (informan) pada wawancara tahun 2018, ibu Kian bercerita bahwa courtyard dulu digunakan untuk menjemur pakaian anggota keluarga atau masak barbeque yang banyak menghasilkan asap. Namun sekarang lebih banyak digunakan untuk menjemur kain-kain batik yang telah melewati proses pewarnaan (Lihat gambar 6). Sedangakan, area dapur yang berada berseberangan dengan serambi belakang, memiliki akses langsung ke courtyard (Lihat gambar 7). Tidak ada perubahan kegiatan yang signifikan pada area dapur, namun adanya penambahan sirkulasi untuk orang nonkeluarga. Karena dapur adalah akses menuju ke area workshop yang terdapat di belakang rumah (Lihat gambar 8).
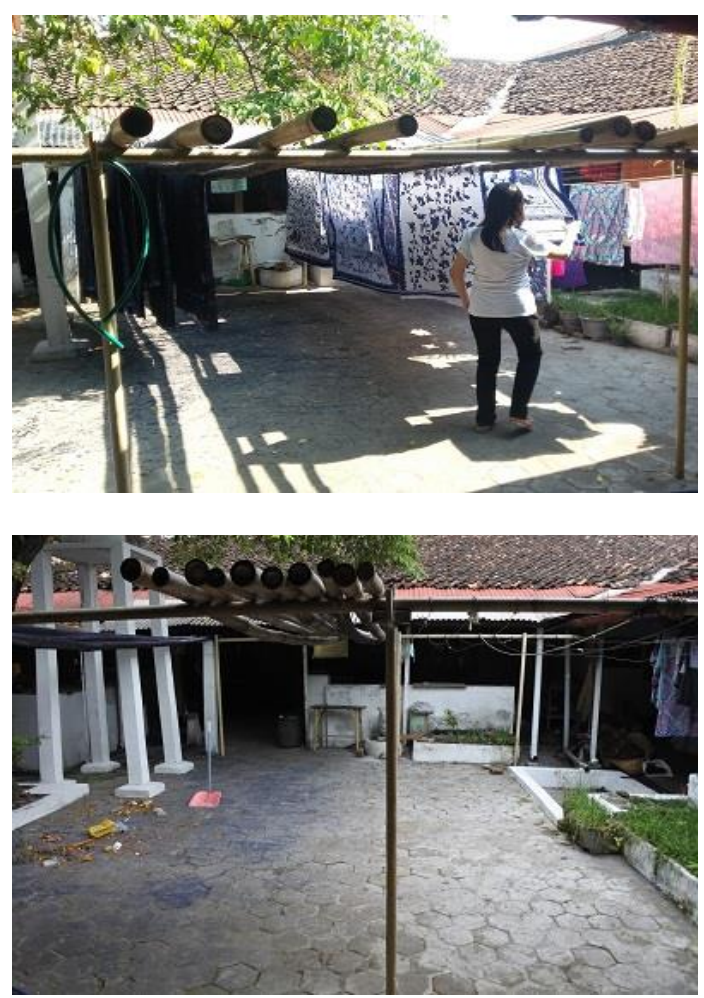

Gambar 6. Courtyard kidang mas

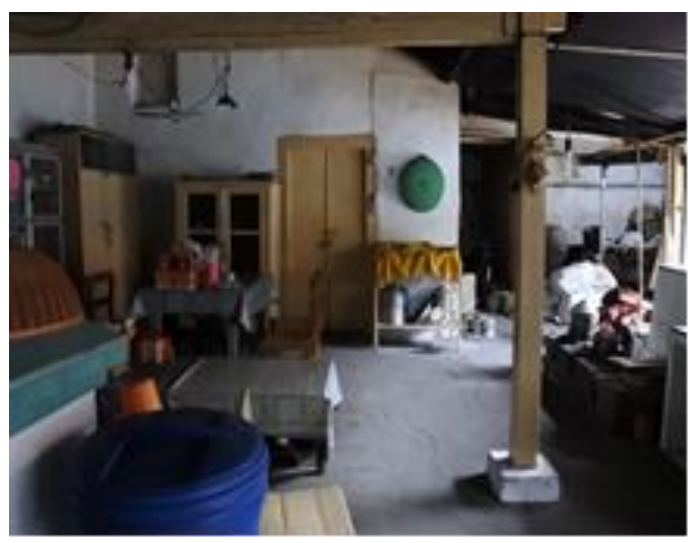

Gambar 7. Dapur kidang mas 


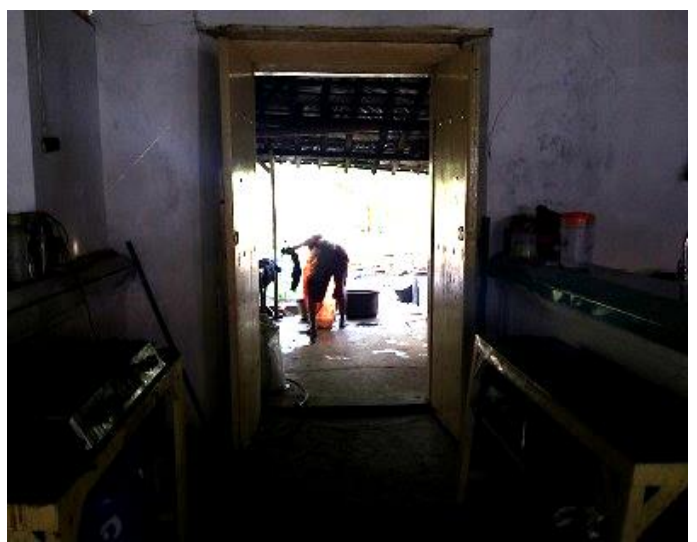

Gambar 8. Akses dari dapur ke workshop

Aktivitas produksi batik tulis Kidang Mas dilakukan di dalam komplek rumah. Workshop menjadi pusat proses membatik dari mulai mencanting, pewarnaan, melorod atau meluruhkan malam atau lilin dari kain dengan cara merebusnya dan mencuci kain supaya lilin lebih bersih dan warna lebih terlihat (Lihat gambar 9). Diperkirakan area workshop ini sudah ada sebelum generasi keempat karena adanya tradisi membuat batik sendiri. Dengan demikian, sirkulasi di workshop hanya untuk keluarga. Tetapi, setelah tahun 1980, ketika Ibu Kian mengizinkan pengrajin masuk ke dalam rumah, area workshop berubah menjadi area publik yang artinya orang-orang nonkeluarga yaitu pengrajin batik "menguasai" nya, begitu juga jika ada pengunjung atau tamu yang ingin mengetahui proses membatik, dapat melihatnya secara langsung.

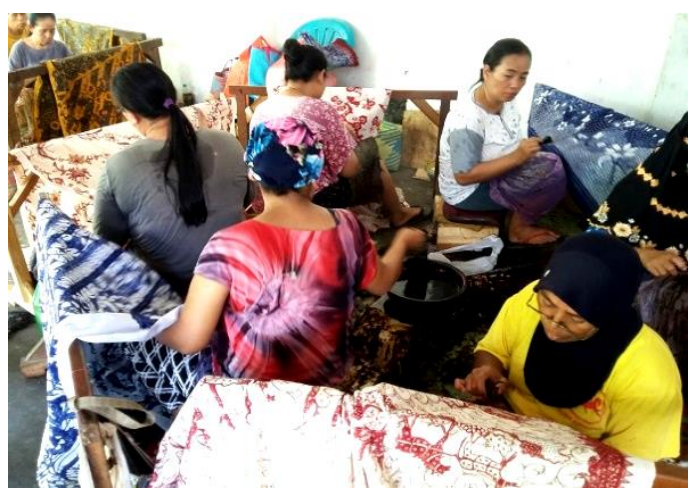

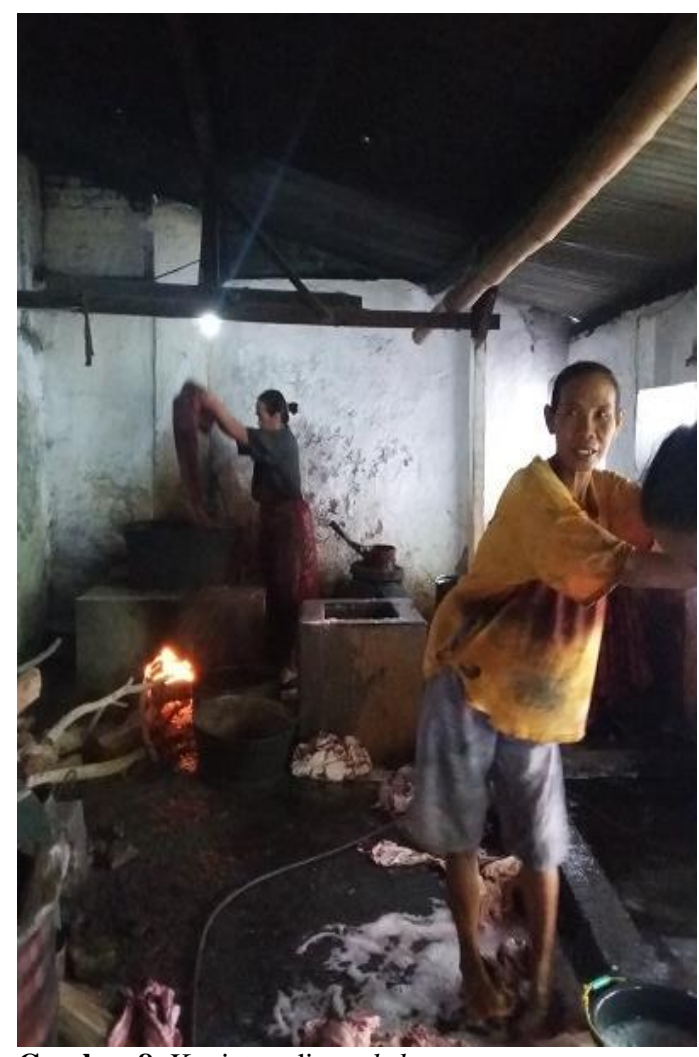

Gambar 8. Kegiatan di workshop

Dari pembahasan dan analisis, diketahui bahwa ruang di dalam sebuah hunian tidak bisa terbentuk secara mandiri, melainkan tercipta selaras dengan keadaan di sekitarnya (Hartono 2019), begitu juga jika terjadi perubahan pada ruang, sudah pasti dipicu oleh perubahan kondisi sekitar. Pada dasarnya manusia membutuhkan ruang untuk menjalankan kegiatannya dan tidak menutup kemungkinan ruang-ruang tersebut berubah apabila terjadi perubahan gaya hidup yang didasari atas kebutuhan (Brenner, NorbergSchulz, and Hall 1972). Pernyataan tersebut sesuai dengan apa yang terjadi di dalam rumah Peranakan Kidang Mas, bahwa perubahanperubahan yang terjadi merupakan respon dari adanya kebutuhan baru yang didukung dengan perubahan gaya hidup serta perkembangan cara berpikir, seperti ketika usaha kerajinan batik tulis dimulai kemudian berkembang dan membutuhkan sirkulasi lebih luas untuk proses pembuatan serta penjualan. Kemudian, perubahan gaya hidup memberikan dampak di bangun rumah Peranakan Kidang Mas seperti fasilitas baru di dalam bangunan utama yaitu kamar mandi, karena permintaan istri pak Rudi dengan alasan supaya lebih dekat dengan kamar dan efisien. 
Sedangkan, perkembangan pola pikir dapat dilihat pada perwujudan perubahan sirkulasi yang semulanya bersifat privat menjadi semi privat atau publik. Perubahan fungsi dan sifat ruang berdasarkan alasan bahwa "manusia harus berusaha lebih menerima tamu, terutama tamutamu yang tertarik dengan batik".

Pelbagai perubahan yang terjadi pada rumah Peranakan Kidang Mas akibat aktivitas berdampak pada sirkulasi di dalam keseluruhan komplek rumah. Perubahan sirkulasi memengaruhi fungsi ruang-ruang di dalamnya. Selama observasi ke lapangan, diketahui bahwa sampai sekarang tidak ada perubahan yang merugikan penghuni. Kidang Mas lebih "terbuka" dengan orang luar, terutama setelah pak Rudi (pewaris saat ini) kembali ke Lasem bersama keluarga. Dengan keterbukaan itu, penghuni rumah Peranakan Kidang Mas merasakan bertambahnya pengetahuan, khususnya tentang heritage building dan batik. Pengalaman juga semakin beragam, karena adanya tambahan interaksi, baik secara fisik dalam bentuk aktivitas, maupun secara intangible berupa pertukaran ide atau konsep dengan obeng maupun tamu. Konsep tersebut secara tidak disadari menambah fungsi dan makna pada ruang di dalam rumah, serta makna bagi penghuni bahkan bagi pengunjung.

\section{Kesimpulan}

Rumah Peranakan Kidang Mas mendeskripsikan bahwa perubahan sirkulasi yang terjadi di dalam rumah sebagian besar memengaruhi fungsi ruang. Namun, cara memandang fungsi ruang bergantung pada pengalaman dan memori masing-masing anggota keluarga/penghuni maupun pengunjung. Hal itu dapat memperkaya sejarah atau cerita masing-masing ruang yang diciptakan oleh pelbagai jejak sirkulasi.

Perubahan yang terjadi di rumah Peranakan Kidang Mas dikategorikan menjadi tiga, yaitu aktif, sedang dan pasif. Berdasarkan analisis, serambi depan dan belakang masuk ke dalam kategori sirkulasi aktif. Banyak kegiatan tambahan yang ada di dalamnya, sehingga merubah fungsi awal yang diperuntukan untuk berkumpul keluarga. Kemudian prayer hall masuk ke dalam kategori sedang, karena ada beberapa fungsi tambahan selain sembahyang tetapi intensitasnya tidak terlalu padat. Begitu juga dengan dan dua kamar di depan telah berganti fungsi menjadi gudang. Sama halnya dengan courtyard dan dapur. Sedangkan, dua kamar tidur di belakang termasuk ke dalam kategori sirkulasi pasif karena masih sesuai fungsinya untuk tidur atau beristirahat.

Faktor penyebab berubahan sirkulasi terbagi menjadi dua yaitu internal yang berasal dari dalam rumah (budaya dan keluarga) dan eksternal yang berasal dari luar rumah (ekonomi dan sosial). Temuan penelitian ini sesuai dengan pandangan Robert A. Dodgshon (1998) yang menyatakan bahwa perubahan sirkulasi yang diikuti perubahan fungsi ruang dapat dikategorikan sebagai: change by expansion dalam hal ini, betul terjadi ekspansi kebutuhan aktivitas, khususnya membatik; kemudian change by replacement (penggantian) seperti kamar tidur menjadi gudang; change by incorporation (penggabungan) dapat dilihat melalui apa yang terjadi di serambi depan, area altar, serambi belakang, courtyard, dapur dan workshop yang fungsinya "digabungkan" antara kegiatan lama dengan kegiatan tambahan/baru (Dodgshon 1998).

Berdasarkan pemaparan di atas, proses keberlanjutan budaya (cultural sustainability) sedang berjalan. Kidang Mas telah berhasil berkompromi dengan waktu, sehingga berhasil beradaptasi dengan lingkungan dan eksistensinya menjadi salah satu ekspresi Lasem yang dipengaruhi oleh keadaan dari keluarga, juga lingkungan sekitar. Seperti yang dikatakan Edward Relph (2018) bahwa tempat adalah ekspresi yang terikat oleh keberadaan dari interaksi/pergerakan manusia tertentu dengan dunia sekitar (Relph 2018). Kemudian, secara tidak sadar, interaksi-interaksi yang menyebabkan perubahan-perubahan tersebut adalah salah satu langkah pelestarian perwujudan tradisi-budaya yang berada di dalam rumah Kidang Mas, yang berusia lebih dari 200 tahun.

Berdasarkan uraian di atas memunculkan saran kepada Pemerintah Daerah untuk memberi perhatian serius terhadap kelangsungan rumahrumah Peranakan Lasem baik dari aspek fisik bangunan maupun content (sejarah dan budaya), sebagai upaya turut menguatkan berbagai usaha pelestarian yang dilakukan pemilik atau penghuni rumah-rumah tersebut. Pedoman pelestarian juga perlu diadakan agar nilai kelokalan baik dilihat dari sisi sejarah, tradisi dan budaya tetap ada, sehingga identitasnya tetap terjaga. 


\section{Referensi}

Arinto, Fransiscus Xaverius Eddy. 2018. 'Pelestarian Arsitektur Berdasarkan Architectural Architypes Melalui Metode Grafis'. ARTEKS : Jurnal Teknik Arsitektur 3 (1): 29-36. https://doi.org/10.30822/arteks.v3i1.52.

Bahauddin, Azizi. 2017. Naratif Dan Protagonis Dalam Reka Bentuk Warisan: Satu Penceritaan Budaya. Penang, Malaysia: Universiti Sains Malaysia. https://books.google.co.id/books?id=qcJoDw AAQBAJ\&pg=PP1\&lpg=PP1\&dq=Naratif + d an+Protagonis+dalam+Reka+Bentuk+Warisa n:+Satu+Penceritaan+Budaya.+Penang:+Pen erbit+Universiti+Sains+Malaysia\&source=bl \&ots=hsqOAMYuUt\&sig=ACfU3U2FSZWy NUm5PH9qzkNc_E36CQmYeg\&hl=en\&sa= $\mathrm{X} \& v e d=2$ ahUKEwjf8tGvyJTqAhVp4XMBH czbDO0Q6AEwAHoECA0QAQ\#v=onepage $\& q=$ Naratif dan Protagonis dalam Reka Bentuk Warisan\%3A Satu Penceritaan Budaya. Penang\%3A Penerbit Universiti Sains Malaysia\&f=false.

Bogdan, Robert, and Sari Knopp Biklen. 1992. Qualitative Research for Education: An Introduction to Theories and Methods. Boston, Berlin: Allyn and Bacon.

Brenner, Art, Christian Norberg-Schulz, and Edward T. Hall. 1972. 'Existence, Space and Architecture'. Leonardo 5 (4): 370. https://doi.org/10.2307/1572613.

Darmayanti, Tessa Eka. 2017. 'Third Space within the Gates of Rumah Peranakan at Chinatown Area, Lasem, Central Java, Indonesia'. In The 5th PSU-USM International Conference On Arts and Sciences, 73-82. Phuket, Thailand: PSUUSM.

https://www.researchgate.net/publication/319 311604_Third_Space_within_the_Gates_of_ Rumah_Peranakan_at_Chinatown_Area_Las em_Central_Java_Indonesia.

Darmayanti, Tessa Eka, and Azizi Bahauddin. 2019. 'Rebuilding Space In Peranakan House In Lasem, Indonesia: Perceived Space Concept'. In, 651-661. https://doi.org/10.15405/epms.2019.12.65.

Djafar, Hasan. 1978. Girindrawarddhana Beberapa Masalah Majapahit Akhir. 2nd ed. Jakarta: Yayasan Dana Pendidikan Buddhis Nalanda.
https://opac.perpusnas.go.id/DetailOpac.aspx ?id=126176.

Dodgshon, Robert A. 1998. Society in Time and Space: A Geographical Perspective on Change. United Kingdom: Cambridge University Press.

Handinoto. 2015. Lasem: Kota Tua Bernuansa Cina Di Jawa Tengah. 1st ed. Yogyakarta: Ombak.

Hartono, Welly. 2019. 'Space Transformation of Dwelling House of Reog Community in Pendukuhan Gunungsari of Bejiharjo Village of Gunungkidul District'. ARTEKS : Jurnal Teknik Arsitektur 4 (1): 13-24. https://doi.org/10.30822/arteks.v4i1.74.

Kant, Immanuel. 1770. 'The Inaugural Dissertation: Concerning the Form and Principles of Sensible and Intelligible World'. Stanford Encyclopedia of Philosophy. 1770. https://plato.stanford.edu/entries/kant/.

Lukman, Christine Claudia, Yunita Setyoningrum, and Sandy Risamntojo. 2018. 'Indonesian Chinese Visual Language Of "Qilin" On Lasem Batik Altar Cloth (Tok Wi)'. Journal of Arts \& Humanities 7 (9): 8494.

https://doi.org/http://dx.doi.org/10.18533/jour nal.v7i9.1488.

Nas, Peter J. M. 2002. The Indonesian Town Revisited. German; Singapore: Lit Verlag; Insitute of Southeast Asian Studies. https://books.google.co.id/books?id=lyB0mH URvIsC\&pg=PA112\&lpg=PA112\&dq=The+ Indonesian+Town+Revisited.+Singapore:+In stitute+of+Southeast+Asian+Studies\&source =bl\&ots=OcXPatxJrP\&sig $=$ ACfU3U2RQRv m-

JWAfxDQ6qxsRGJhXo8kaA\&hl=en\&sa=X \&ved=2ahUKEwjiqumOuJTqAhWHXSsKH e9sBXsQ6AEwBHoECF8QAQ\#v=onepage $\& q=$ The Indonesian Town Revisited. Singapore\%3A Institute of Southeast Asian Studies\&f=false.

Nastiti, Titi Surti, and Nurhadi Rangkuti. 1988. 'Ekskavasi Caruban, Lasem, Jawa Tengah No. 38 '.

Jakarta. http://repositori.kemdikbud.go.id/3383/1/Beri ta Penelitian Arkeologi No.38..pdf.

Nur, Abdul. 1955. 'Lasem, Kota Pondok'. Teruna: Madjalah Remadja, 1955.

Pallasmaa, Juhani. 2009. 'Space, Place, Memory and Imagination: The Temporal Dimension of Existensial Space'. In Spatial Recall: Memory 
in Architecture and Landscape, edited by Marc Treib, 268. New York: Routledge.

Purwanto, L.M.F., and Yulita Titiek S. 2017. 'Acculturation in the Architecture of Lasem City'. Asian Journal of Engineering and Technology 5 https://doi.org/10.24203/ajet.v5i2.4711.

Rachmayanti, Sri, Christianto Rusli, and Anak Agung Ayu Wulandari. 2017. 'Cultural Acculturation in Interior and Architecture of Old Straits-Born Chinese Lasem House'. $\begin{array}{lll}\text { Humaniora } & 8 & \text { (3): } 279 .\end{array}$ https://doi.org/10.21512/humaniora.v8i3.371 8.

Relph, Edward. 2018. 'Speculations about Electronic Media and Place'. Environmental \& Architectural Phenomenology 29 (1): 1418.

https://newprairiepress.org/cgi/viewcontent.c gi?article $=1082 \&$ context=eap .

Smith, Dianne J. 2001. 'Interior Architecture as a Storied Life: Narrative-Research and the Built Environment'. IDEA $1 \quad$ (2). https://www.researchgate.net/profile/Dianne Smith6/publication/27468460_Interior_archit ecture_as_a_storied_life_Narrativeresearch_and_the_built_environment/links/5 722f05908aef9c00b7c8b62/Interiorarchitecture-as-a-storied-life-Narrativeresearch-and-the-built-environment.pdf.

Smith, Richard J. 2015. The Qing Dynasty and Traditional Chinese Culture. Lanham, Maryland, London: Rowman \& Littlefield Publishers.

https://books.google.co.id/books?id=RhmaCg AAQBAJ\&pg=PR4\&lpg=PR4\&dq=The+Qin g+Dynasty+and+Traditional+Chinese+Cultur e.+London,+UK:+Rowman+\%26+Littlefield + Publisher, + Inc \& source $=$ bl\&ots $=$ wSD4PNQ 2DH\&sig=ACfU3U1i_AK6166P0PLwpcCva iDpE0KBEA\&hl=en\&sa $=$ X\&ved $=2 \mathrm{ahUKEw}$ iYuO6AxpTqAhX1heYKHbiOAh4Q6AEwA XoECDMQAQ\# $v=$ onepage $\& \mathrm{q}=$ The $\quad$ Qing Dynasty and Traditional Chinese Culture.
London\%2C UK\%3A Rowman \%26 Littlefield Publisher\%2C Inc\&f $=$ false.

Soja, Edward W. 1998. 'Thirdspace: Journeys to Los Angeles and Other Real-and-Imagined Places'. Capital \& Class 22 (1): 137-39. https://doi.org/10.1177/03098168980640011 2.

Sudarwani, M. Maria, Edi Purwanto, and Siti Rukhayah. 2018. 'Akulturasi Dalam Arsitektur Rumah Tinggal Lasem,Studi Kasus: Rumah Liem King Siok'. Sabda: Jurnal Kajian Kebudayaan 13 (2): 158. https://doi.org/10.14710/sabda.13.2.158-168.

Sudradjat, Iwan. 2020. 'Teori Dalam Penelitian Arsitektur'. ARTEKS: Jurnal Teknik Arsitektur 5 (1): $\quad$ i-vi. https://doi.org/10.30822/arteks.v5i1.378.

Sukada, Nabila, and Purnama Salura. 2020. 'Basic Architectural Expression of a Cultural Center, Study Object: Volkstheater Sobokartti in Semarang, Indonesia'. ARTEKS : Jurnal Teknik Arsitektur 5 (1): 11-20. https://doi.org/10.30822/arteks.v5i1.76.

Sumardiyanto, Bonifasius. 2019. 'Pengaruh Renovasi Terhadap Makna Rumah Tradisional Masyarakat Jawa, Kasus Studi: Kotagede Yogyakarta'. ARTEKS: Jurnal Teknik Arsitektur 3 (2): 113-28. https://doi.org/10.30822/arteks.v3i2.62.

Suroyo, Agustina Magdalena Djuliati. 1994. 'Sejarah Dan Budaya Maritim Di Lasem'. Semarang.

Utomo, Avif Arfianto Purwoko. 2017. 'Potensi Bahari Lasem Sebagai Sejarah Maritim Lokal'. SEJARAH Dan BUDAYA: Jurnal Sejarah, Budaya Dan Pengajaranya 11 (2): 141-50. http://journal2.um.ac.id/index.php/sejarahdan-budaya/about.

Wilson, Forrest. 1972. Structure: Essence of Architecture Hardcover. First. United Kingdom: Littlehampton Book Services Ltd. 